\title{
Clinical education of occupational therapy students: reluctant clinical educators
}

\author{
Patricia De Witt, Dip OT (Pret), MSC OT (Wits) \\ Adjunct Professor and Head, Department of Occupational Therapy, School of Therapeutic Sciences, University of the \\ Witwatersrand
}

\author{
Alan Rothberg, MBBCh (Wits), FC Paed (SA), PhD (Wits) \\ Associate Professor, School of Therapeutic Sciences, Faculty of Health Sciences, University of the Witwatersrand
}

Judith Bruce, B Cur (UWC), MSc Nursing (Wits), PhD (Wits)

School of Therapeutic Sciences, Faculty of Health Sciences, University of the Witwatersrand

Clinical education is essential to the development of clinical and professional competencies in occupational therapy students during the mandated 1000 hours of clinical practice. Students' concerns about the quality of their clinical education were raised during a routine HPCSA accreditation visit. These concerns resulted in a qualitative study which used hermeneutic phenomenology as the strategy to explore, examine and understand the 'lived experiences' of clinical education within the context of occupational therapy practice by those who provide it and who receive it.

Focus groups were used to collect the data. The purpose of the focus groups was for the participants to discuss and reflect on their experiences and to identify the factors that framed those experiences and perceptions. The three groups of eight participants from each of the following: the final year students $(n=32)$, the on-site clinical educators who had supervised final year students $(n=43)$ and from the university clinical educators $(n=12)$, were invited to participate.

Data from the focus groups were analysed within and across the focus groups using open and then axial coding. Three themes emerged. This paper only reports on the code: Reluctant Clinical Educators within Theme 2: Challenges to quality.

Reluctant Clinical educators were highlighted in each focus group and the impact of this reluctance on clinical education is described.

Key words: quality of clinical education, poor role models, time, students as learners

\section{INTRODUCTION}

The University of the Witwatersrand (Wits) was the first university in South Africa to offer an occupational therapy undergraduate education programme. The programme has evolved and currently runs as a four year, full time, BSc programme using a hybrid problem-based learning (PBL) teaching strategy which aims to graduate a generalist occupational therapist with entry level skills and competence.

The programme is designed so that the clinical curriculum is embedded in the theoretical curriculum, with students completing blocks of clinical work at strategic periods within the coursework. This aims to facilitate the transitioning of theoretical knowledge into clinical skills and competence. Students do clinical work from year one, but the time spent at clinical sites increases throughout the programme, with most of the final year being spent in a variety of clinical sites. Students complete 256 more than the mandatory 1000 clinical hours ${ }^{1,2}$. Each block of clinical work is designed as a discrete clinical learning experience with its own learning outcomes and requirements, collectively leading the students towards achieving the exit level outcomes for the programme. Final year students complete eight clinical blocks throughout the year in order to gain experience in the main fields of practice: occupational dysfunctions in clients with mental health problems, occupational performance dysfunction in clients with physical health problems, occupational dysfunction in children, and occupational therapy for individuals or groups at risk for occupational dysfunction or with occupational dysfunction on the primary care platform (public health).
Throughout the programme students complete their clinical work under the guidance of a clinical educator $(C E)^{3}$. In the first three years the clinical education of students is largely the responsibility of university employed staff, while in the final year this is the responsibility of on-site occupational therapists employed by the clinical education sites. The university staff visit the final year students only twice during a block at the time of the students' formative and summative evaluations.

During the 2009 Health Professions Council of South Africa (HPCSA) visit to accredit the Wits occupational therapy programme, final year students raised concerns regarding the quality of their clinical education as well as their experiences at some of the clinical education sites. Due to the nature of the concerns the occupational therapy department conducted a survey amongst the final year students to document these concerns. Although students recognised that some on-site clinical educators had contributed greatly to their learning, their three greatest concerns were: limited availability of the CE (reported by $74 \%$ of the class) which raised questions about a lack of learning opportunities and how clinical performance was evaluated if the CE was not around to observe the student; CEs having limited teaching and evaluation/assessment skills (67\%) with students reporting that CEs could not help them translate classroom theory into practice due to lack of, and inflexibility about, the new knowledge and therapy techniques that they had been taught, and a disregard for the importance of evidence-based practice. In addition students perceived CEs as having very little sensitivity to, and understanding of, their inexperience and emerging competency in the skills they were 
supposed to be developing, with CEs expecting students to have the same knowledge and skills as themselves. A number of students believed that their clinical marks were influenced by the CE's perception of them as individuals rather than on the quality of work they did; negative attitudes towards the students (reported by $56 \%$ ) included using students to do the jobs CEs did not like, and giving to students clients that CEs could not cope with or disliked, negative attitudes about the university and the information that they were being given, and insensitivity to student difficulties and clinical anxieties. This was perceived by the students as a lack of professionalism on the part of the CEs.

These concerns had been raised previously at the regular student-staff meetings with students and had been a consistent topic at the end of block debriefing sessions run by a psychologist from the Wits Counselling and Careers Development Unit (CCDU) over a four year period. Similar concerns were raised by colleagues from other universities at inter-university professional meetings. However there was no concrete evidence to support these concerns and reports were based on hearsay and therefore difficult to address and resolve $e^{4,5}$.

In order to deal effectively with these problems which compromise the quality of students' clinical education, it was important to collect empirical evidence in the context of professional practice so that the problems could be understood and solutions explored from the perspective of all role players: students, on-site CEs and the university staff. Only then would it be possible to introduce interventions to ensure that the clinical education that students receive is fair, appropriate, effective, efficient and manageable.

\section{LITERATURE REVIEW}

Clinical education is recognised as being essential in the process of learning to be an effective professional ${ }^{6,7}$. It is an educational process that involves the translating of occupational therapy classroom knowledge into clinical knowledge, skills and attitudes that are appropriate to individuals and groups of clients and service delivery in a variety of different practice settings ${ }^{7-9}$. This learning process takes place under the guidance of a CE who is a key role player in the success of this process. Costa ${ }^{8}$ and Higgs and McAllister ${ }^{10}$ recommend that health professionals should not take on clinical education until they are experienced and professionally ready.

The HPCSA and the World Federation of Occupational Therapists (WFOT) provide a time-linked guideline of between 6-12 months of clinical experience before undertaking clinical education $^{1,2}$. The American Occupational Therapy Association (AOTA) has developed a set of $C E$ role competencies which describe the knowledge, skills and attitudes needed by an occupational therapist before undertaking the role of $C E$. These include: knowledge about clinical education; clinical reasoning needed to promote the clinical education process, the interpersonal skills to develop an appropriate CE-student relationship; proficiency in the skills related to planning, executing, reflecting on and evaluating a clinical education experience; and identifying and analysing ethical issues and problems associated with clinical education that need to be managed in a teaching and learning context $\mathrm{t}^{8,11}$. Research by Mc Allister ${ }^{12}$ suggests that professional readiness to be a CE is far more complex than just attaining knowledge and some experience, and is dependent on the development of one's professional sense of self (self-awareness, self-knowledge and self-acceptance). Costa recommends that occupational therapy clinicians should supervise their first student only when they have achieved a competency level of professional development which is the third level Dreyfus's model of skill acquisition. At this competency level, they are regarded as a self-confident, competent or proficient practitioners ${ }^{13}$. However, Costa cautions that being a good clinician is no guarantee that the individual will be a good CE, as clinical education is an intervention in its own right that is supported by its own body of knowledge ${ }^{8}$.

In South Africa, while some occupational therapists may choose to take on the role of $\mathrm{CE}$, in many instances this role is an expected requirement of the job in public sector facilities, especially if the therapist is working at a site on the Wits clinical training platform. It is problematic that, relatively inexperienced community service therapists, especially those working on the primary care platform, often become CEs when they are not ready for this critical role. The reality is that of the 43 CEs contributing to the final year clinical education in $2013,42 \%$ had less than three years of experience $(n=18)$ and a further $7(16 \%)$ had less than 5 years of experience.

The study reported in this article was the first step in a larger sequential explorative mixed methods project which aimed to study clinical education in the context of service delivery ${ }^{14}$. The purpose was to examine the perception from the perspective of the three groups of role players: students, on-site CEs and the university staff of the factors which influence quality clinical education.

\section{RESEARCH METHOD}

A qualitative research method of inquiry involving hermeneutic phenomenology as the strategy was used to explore, examine and understand the 'lived experiences' of clinical education in the complex world of occupational therapy practice by the participants who gave clinical education and those who received it $^{14-16}$.

Focus groups were used to collect the data because focus groups provided a safe and social context in which to think, talk and reflect on experiences of, and feelings related to, clinical education ${ }^{17-19}$. The purpose was for participants to discuss and reflect on their 'lived experiences' of clinical education (whether positive or challenging) to try to identify the factors which framed their experience and perceptions.

\section{Population and sample}

The population from which the participants of this study were drawn consisted of all clinical education stakeholders on the Wits clinical training platform: final year OT students $(n=32)$, on-site CEs $(n=43$ estimated) and university staff $(n=12)$.

Eight participants were selected differently for each of the three stake holder groups. The student group was randomly selected from the females in the final year class. In terms of the ethical clearance requirements the two male students in the class had to be excluded from the study as they could be easily identified. Purposive and stratified sampling was used to select the on-site and university CEs. Purposive sampling was used as the participants needed to have been involved in the clinical education of final year students. The sampling was stratified to ensure that $C E s$ of all fields of practice were included in the participant groups so as to gain deep and rich data ${ }^{20}$. The recruitment process used with these two stakeholder groups was also slightly different. To recruit the on-site $C E$ group all the final year student clinical sites $(n=22)$ were listed on slips of paper. The sites were colour coded according to the main fields of practice and placed in a box. The departmental secretary was asked to draw out two site names for each colour and telephone the head of department. The head was asked to identify willing participants from her site. This process was continued until there were eight participants, two from each field of practice. The university staff stakeholder group was selected from the university employed permanent staff. The departmental secretary drew names out of a hat, one per field of practice, until there were eight consenting participants and each field of practice was represented.

\section{Data Collection}

The data collected in the focus groups were audio-taped to record the contextual information, and a socio-gram was used to record the group process, conversation exchange and group dynamics ${ }^{21}$. A group protocol was developed for the focus groups, not to direct the group discussion but to ensure that the group process in each of the focus groups was similar and to stimulate group interaction. The 'funnel design' described by Hennink, Hutter and Bailey was used to structure the focus group ${ }^{22}$. No questions 
were prepared to direct the discussion on clinical education as the researcher did not want to bias or lead the discussion in any way. Her role was to facilitate discussion and clarify issues. In view of the sensitive nature of the subject special attention was given to the development of a safe and accepting group climate and the group process, which was recorded as field notes on a socio-gram by a co-researcher. The 'warm up activity', which was used to effect the emotional climate of the focus group and introduce the topic, was completed in dyads, aimed to assist participants to reflect on their 'lived experience' of clinical education and identify their thoughts, understandings, feelings, concerns, expectations and views. Each dyad was asked to select two factors which they believed influenced the quality of clinical education. These factors formed the basis of the group discussion but were not used as priori codes when the data were analysed. The data were considered saturated when no new issues related to the quality of clinical education were introduced across the three groups, even if the views that were held were variant ${ }^{23}$.

\section{Ethical considerations and trustworthiness}

This research was approved by the University's Human Research Ethics Committee. Permission for on-site research was also granted by the Gauteng Departments of Health and Education, and the Dean of the Faculty of Health Sciences approved the participation of the final year students as well as the staff of the Department of Occupational Therapy. All participants gave written consent to participate and for the focus groups to be audio-taped.

The trustworthiness of the research was assured by applying the principles of credibility, dependability, transferability and confirmability ${ }^{24,25}$. Reflection was used during the data analysis by considering the contextual data together with the group conversational and group dynamic data so as to consider both the latent and manifest content of the focus groups ${ }^{26}$. An audit trail recorded all the steps and decisions that were made during the research process ${ }^{27}$.

\section{Data Analysis}

The demographic characteristics of the focus group participants were described using percentages, means and ranges.

The focus groups were analysed within and across the stakeholder groups. To achieve this all transcripts were read carefully by the researcher to reduce and distil the data by identifying first open and then axial coding units ${ }^{23,24}$. A process of aggregation followed whereby the coding units were grouped into inductive and in vivo codes $^{24}$. These were listed in a code book together with a description of each code. A research assistant followed the same process and independently developed a set of codes. These were compared to those of the researcher and the codes and descriptors were modified on the basis of a discussion to confirm the validity of the codes ${ }^{22}$.

The data were then entered into QSR International $\mathrm{N}$ Vivo 9 version 9.2.70.0(32-bit). The data were re-analysed, some codes were merged into other codes and the codes were organised into themes and categories within each theme which were considered to be the "structures of experience"28:78. A roadmap was drawn as a visual representation of the themes that emerged from the data. On the basis of the roadmap the themes were again reorganised and a data search was undertaken to ensure that the text supported and verified the emerging themes and categories, and all issues that were raised by the participants were classified ${ }^{22}$. Finally transcripts were re-analysed and compared with socio-grams to obtain thick and rich data by describing the meaning, perspectives and concerns about clinical education that were raised within their social context ${ }^{22}$.

\section{RESULTS}

Three focus groups were completed, one for each group of stakeholders. Although a sample of 24 was planned and additional on-site CE attended the focus group thus a sample of 25 participants was included in the focus groups.

\section{Demographic characteristics of focus group participants}

\section{Student Stakeholder Group $(n=8)$}

All participants were female and their ages ranged from 2 I - 23 years with mean age of 21.7 years. Six students reported that occupational therapy was their first choice of career and six had entered the programme directly from school. One student had failed a year, thus seven students were in their final year in the minimum time. Most students rated their own academic and clinical performance in the middle third of their class.

\section{Clinical Educator Stakeholder Group $(n=9)$}

Although eight CEs had confirmed attendance, nine CEs arrived and participated in the focus group. All participants were female; eight were between $2 \mathrm{I}$ and 30 years while the remaining one was one year older. Seven participants had graduated from Wits and were therefore familiar with the course structure and the clinical block requirements. Two participants had completed post graduate diplomas. Their clinical experience varied from less than one to ten years with a mode of five years. All participants worked full time, eight worked in public sector CE sites and one in a private hospital. The fields of practice were equally represented in the sample. The group had collectively been responsible for the clinical education of 47 students during the academic year with a mean of 5.9, although the most senior CE had supervised no students in the year and the most-inexperienced CEs had been responsible for the highest number of students $(n=2 I)$.

\section{University Stakeholder Group $(n=8)$}

Again all participants were female. Participants in this group were older than the group of clinical educators, with only one below 30 years, five between $3 \mathrm{I}$ and 40 and two over 50 . Four had Masters level qualifications and one a PhD. Four participants had had more than 5 years of academic experience and 2 had been lecturing for more than 20 years. Seven participants worked full time and one part time and the only field of practice not represented was public health. During the past academic year the university staff had been involved in the clinical education of 109 final year students (formative and summative evaluations) the number varying from 7-20 students with a mean of 13.6 .

\section{Findings of the Focus Groups}

Three themes emerged from the collective data from the three groups of participants. These themes described the participants' perceptions of the factors impacting on the quality of clinical education. The themes were:

$*$ Theme I - Pockets of excellence. The essential features of this theme were that good CEs formed excellent CE-OTS relationships, facilitated student learning in a positive way and role modelled good practice.

* Theme 2 - Challenges to quality. This theme recorded the participants' perceptions of the factors which negatively influenced quality clinical education on the Wits clinical training platform. All the concerns that were reported by the students during the 2009 HPCSA accreditation visit were raised in each focus group, but these will not be reported in this paper.

* Theme 3 - 'Grapevine'. The essential features of Theme 3 was that there is an informal and sometimes instant communication system within each stakeholder group that informs and misinforms members about CE education issues which create misperceptions and biases.

However this paper will only report on a single code that emerged from Theme 2: Reluctant CEs. This code is of particular importance because $54 \%$ of CEs on the Wits teaching platform reported that clinical education was an expected part of their job which they did not really want to do. This would classify them as reluctant CEs. This topic thus appeared to be worthy of an independent report. 


\begin{tabular}{|c|c|c|}
\hline Theme & Categories & Sub-categories codes \\
\hline \multirow{17}{*}{ Theme 2: Challenges to quality of clinical education } & \multirow{4}{*}{$\begin{array}{l}\text { 2.I Poor role models } \\
\text { (in vivo code) }\end{array}$} & Is this Occupational therapy? \\
\hline & & The ethos of work \\
\hline & & Sinking into the quagmire \\
\hline & & Experience versus competence \\
\hline & \multirow{4}{*}{$\begin{array}{l}2.2 \text { Reluctant CEs } \\
\text { (inductive code) }\end{array}$} & Lack of desire to teach and facilitate learning \\
\hline & & Use of power and authority \\
\hline & & I suffered so you will too \\
\hline & & Disempowering students \\
\hline & \multirow{2}{*}{$\begin{array}{l}\text { 2.3 The clinical curriculum } \\
\text { (inductive code) }\end{array}$} & What do the requirements mean? \\
\hline & & Marks versus learning \\
\hline & \multirow{5}{*}{$\begin{array}{l}\text { 2.4 Students as learners } \\
\text { (inductive code) }\end{array}$} & Student diversity \\
\hline & & Poor coping skills \\
\hline & & How students learn \\
\hline & & Why do students not know? \\
\hline & & Role of marks \\
\hline & \multirow{2}{*}{$\begin{array}{l}2.5 \text { Time } \\
\quad \text { (in vivo code) }\end{array}$} & Time to learn \\
\hline & & Time to help students learn \\
\hline
\end{tabular}

The lack of desire by CEs to teach and facilitate students' clinical learning was reported by participants of all three focus groups as one of the factors that influenced the quality of clinical education. As can be seen from Tablel this was one of the categories that emerged from Theme 2: Challenges to the quality of clinical education. Four sub-categories emerged from this category, the first being: a lack of desire to teach and facilitate learning. Conversations reflecting this sub category were evident in each of the three focus groups:

Clinician 9 reported ".one of the OTs in our department... she hates the students. She doesn't let our students know because she can't, but she just hates them. I think that some people are naturally able to get their knowledge across to other people and others just aren't". Another clinician stated that she believed that "some people have the ability to teach and other people do not" [Clinician 2].

This sentiment was also echoed by the university participants: "...the clinical teaching is happening by people who are not teachers and who have not chosen to be teachers 'Oh the students again: do I have to do it.?' But they are in a position where they are expected to teach students where that is not their main focus or need or want" [University participant 4]. "They are good at their clinical work but they are not able to teach. [University participant 6]. "Is it because they don't have the supervisory skills that they can't supervise or is it just that they are disinterested?" [University participant 3].

Students perceive that clinical education"...may be a lot of work (for supervisors) and that it is a chore ....and that is why maybe I don't think a lot of them love supervising" [Student 6]. Students perceive this reluctance in the attitude of clinical educators towards students. "I feel like they almost do not want to get involved, they don't want to know, they do not want to get too involved with you, they do not want to know you and what you are going through or help you" [Student 8]. Students perceive that they "...cannot learn without supervision" [Student I] and that they need feedback. "I did not get any feedback before my final...like my theory was wrong. So in that sense I thought it would be really helpful to get in my practical" [Student 5].

Students interpreted this reluctance as the CE being unapproachable and unavailable which negatively influences the CE-student relationship and ultimately the learning experience. "...it is all about the supervisor being approachable... if a supervisor is approachable you have respect for them ... you can ask questions... and ask will this work?" [Stu- dent 2]. If they are not approachable ...I mean you have so many questions you don't know where to start.....you just try to figure it out by yourself"' [Student 3]. "You get [supervisors] that just think that they can crush you and you can take on their work on top of what your requirements are and that is not cool, it's just like they don't want to help you" [Student 6].

The second sub-category 'The use of power and authority' was reflected in students' perception that reluctant supervisors use their power and authority to control and put students down. "... some supervisors like that power because they want you to know that you are down there and subordinate and they are up there and have the power and you have to respect them." [Student 2]. Supervisors also use their authority to criticise students' appearance. "...you have nail polish on; you will take it off. And you have too much makeup on. And those of you who know me really know that I do not wear a lot of makeup." [Student 6].

The third sub category was: I suffered so you will too.

The perception that CEs treat students as they were treated was expressed in the focus groups. "How do you supervise somebody when the role model [supervisor] you had was terrible and you were beaten to pulp as a student. You do the same to the student!" [University supervisor 4]. The students supported this view: "Because they are working as a community OT supervisor they give you hell when they were just there last year. I can't understand it [Student 7].

The final sub-category reported how students feel disempowered in the clinical education situation. "We as students... really don't have much power to say [anything]. It would backfire on us second to none if we did so" [Student 8]. "Even though we have been taught to assert ourselves and even if you feel not happy with your supervisor... you dare not open your mouth because at the end of the day...every single thing you do is marked. If you open your mouth once, not even to be rude but to say I do not think this is right or something, they take notes ... and I would rather suck up to the supervisor and do well than open my mouth and say what I have to say and do badly" [Student 7].

Students also perceive that at some sites the marks that are achieved have no reflection on their clinical performance. "If you are at $X$ (clinical site) everybody knows ... if she likes you you pass, if she doesn't you fail and I don't think that's fair at all..." [Student 3].

\section{DISCUSSION}

Professional literature affirms that the only way students learn the necessary professional skills and competencies is in an appropriate 
clinical setting ${ }^{29}$. The key contributor to quality clinical education is the nature of the clinical education process and the engagement of both the student and the CE in this process ${ }^{11,30}$. Health professionals have always been expected to teach, motivate and ensure that students have the required competencies for practice. This role is included in the job description of all public sector occupational therapists although the job descriptions do not detail what this should include or the percentage of time that that should be dedicated to this ${ }^{31}$. However the service delivery pressures and the increase in student numbers has in turn increased the demands of this dual role on on-site clinical educators ${ }^{8,31,32}$. Clinical educators reported that clinical education takes time and takes them away from their primary role of treating patients. Clinical managers in a later stage of this study also expressed concern at the time clinical education takes ${ }^{33}$.

The findings suggested that CEs may not know how to help students transition their classroom knowledge into practice and in some case may not wish to be involved with students at all. Clinical educator's knowledge and skill may be limited to how they were taught in the context of their clinical experience as students and that this may be a source of their reluctance. Clinical education itself has a developing body of knowledge, and knowledge of educational principles and processes are becoming essential for professionals involved in the professional development of students in the clinical setting. Most health professions including occupational therapy are advocating that clinical educators attain basic knowledge and skill in teaching and learning when they become clinical educators ${ }^{11,31,32,34,35}$.

A Canadian study identified stress as being a major factor in why physiotherapy clinicians were reluctant to be involved in the clinical education of students. The stresses went beyond time and service pressures and included the stress of being judged by students as being underprepared as CEs, being intimidated by the new knowledge that students bring, and clinical experience being challenged in the light of new evidence and professional developments ${ }^{36}$.

Since the clinical education process is not seen by clinical staff to be a valuable source of future staff, the link between good clinical education and good clinical outcomes as a professional investment appears not to be well recognised or valued by the occupational therapists on the Wits teaching platform. Given similar anecdotal feedback at inter-university professional meetings, it appears that this problem is not unique to Wits. This is contrary to findings in other countries where clinical departments actively participate in clinical education for staff recruitment purposes ${ }^{36,37}$ and may relate to the fact that new graduates completing their community service year are assigned to occupational therapy departments rather than being selected and clinical heads report having little influence over the appointment of staff to other vacant posts.

While there is literature describing the reasons why on-site clinical educators agree to or do not wish to be involved in clinical education, there is little literature on those who do not wish to be involved but are pressured to do so due to the mandatory requirements of their job description. International literature also suggests that this should not happen until the individual clinician is ready to do so ${ }^{8,38}$. While it may be advantageous to wait for clinical staff to be professionally ready to take on the clinical education of students the reality of the South African situation, for the foreseeable future, is that this will remain a problem until there are sufficient clinical staff with experience in the public sector clinical education sites willing to deal with the increasing student numbers.

In the quantitative aspect of the mixed study that followed the qualitative study reported here most CEs believed that it was their professional responsibility to contribute to the clinical education of students. In spite of this belief many are reluctant although the precise reason for the reluctance is uncertain. One can speculate that in the light of the profile of the CEs on the Wits teaching platform, the fact that many of these clinicians are young, and still in the beginner-stage of their professional development that they may therefore not be quite ready to be involved in clinical education. However this reluctance was also expressed by $50 \%$ of the experienced CEs that participated in the study, and although this number is small and not generalisable to all CEs it is never-the-less of concern and much higher than was expected and may need considerable attention in the future to mitigate this.

There is a perception that the divide between university and the clinical services in terms of practice and the theoretic requirements for practice is wide, in spite of the co-operative relations that are in place. This view suggests that on-site clinicians believe that it is the universities' responsibility to educate and therefore clinical education is also their job. This is to some extent supported by the reluctance of clinical staff to take responsibility for the junior students ( $I^{\text {st }}$ to $3^{\text {rd }}$ years) and the university department providing outside tutors to take responsibility for these students. There are a number of clinical placements, especially the school for children with special needs, who have offered to accommodate students but will not do any clinical teaching or activities associated with this role. The implication is that the university staff should do this. It raises the question as to how effective it is to teach clinical competence if the teacher does not know the client or have access to the school records and information that might inform practice and what would be the ethical implications of this?

Financial rewards for clinical education have also been a consideration, which have been raised from time to time by the university and on-site clinical educators. The Hall study on Canadian physiotherapists also explored this but the result demonstrated that clinical educators did not want to be paid but to be acknowledged and thanked ${ }^{36}$. Currently CEs can be credited with a maximum of 16 Continuing Education Units (CEUs) in a year depending on the number of students in their care. Access to the university library and reduced costs for short and formal courses have also been frequent requests but this is not possible unless there is a formal joint appointment. In this context the reluctance of CEs to entertain the possibility of honorary university posts (joint posts) and more collaborative activity around service, research or education is difficult to comprehend.

Students are aware that some CEs are reluctant. This reluctance impacts on the CE-OT student relationship, their clinical learning as well as their experience within the clinical block. Students believe that they have to be extra careful in the way they behave, and in what they do and say as this has a direct influence on their evaluation and block marks. They experience this as an additional stress over and above the stress of their clinical learning. While professional learning and attaining a degree inherently promotes an increased level of stress, the promotion of a desire to be a life-long learner will be negatively influenced if the stressors in the clinical learning environment are extreme.

The results of this qualitative aspect of the study were expected to start an exploration of the factors influencing the quality of the clinical education provided on the Wits teaching platform rather than draw precise conclusions. The sample for a qualitative study was by nature small and in this case limited by the fact that the sample was not representative in terms of gender, although the number of males in the profession is very small.

\section{CONCLUSION}

Clinical education is essential to an OT student developing the appropriate competencies, but the process is complex. Clearly the on-site clinical staff are the best placed to ensure that students attain these professional competencies and clinical teaching is essential to this. In addition the role that CEs play as professional gate-keepers cannot be overemphasised. While there are many CEs that enjoy this role and contribute greatly to the clinical education programme, the fact that so many do not wish to do this and this reluctance is played out in how this role is executed is of great concern to the students in training but also in the longer term for the development of the profession. 
One of the aims for the larger mixed methods study was to explore whether a specific CE preparation programme to better prepare on-site clinical staff for the educational components of this process, as is done in many countries in the world. Considerable work is needed before this can be done and the effectiveness of such a programme will have to be carefully and consistently monitored. This may not greatly reduce the number of on-site CEs who are reluctant but perhaps better prepare those who are reluctant for this role. Further research into understanding the causes and effects of reluctance amongst OT on-site CE is needed so as to ensure the quality of clinical education for all students in the production of an effective occupational therapy work force.

\section{REFERENCES}

I. Hocking C, Ness N. Revised Minimum Standards for the Education of Occupational Therapists: World Federation of Occupational Therapists, 2002.

2. Health Profesions Council of South Africa Professional Board for Occupational Therapy Medical Orthotists and Prosthotists and Art Therapy. Minimum Standards of Training for Occupational Therapists, 2010.

3. Health Professions Council of South Africa. Standards of Practice for Occupational Therapists Pretoria, 2006.

4. Sweeney G, Webley P, Treacher A. Supervision in Occupational Therapy, Part I: The supervisors anxieties. British Journal of Occupational therapy, $200 \mathrm{la}$; 64(7): 337-45.

5. Sweeney G, Webley P, Treacher A. Supervision in Occupational Therapy, Part 2: The Supervisee's Dilemma. British Journal of Occupational therapy, 200 Ib; 64(8): 380-43I.

6. Bester J, Beukes S. Assuring Quality in Clinical Education. South African Journal of Occupational Therapy, 20I I; 4 I (3): 30-4.

7. Best D. Exploring the Role of the Clinical Educator. In: Rose M, Best D, editors. Transforming Practice through Clinical Education, Professional Supervision and Mentoring. Ist ed. Edinburgh: Elsvier Churchill Livingstone; 2005: 45-8.

8. Costa D. Clinical Supervision in Occupational Therapy: A Guide for Fieldwork and Practice. I ed. Bethesda: American Occupational Therapy, Inc., 2007.

9. Mc Allister Lindy. An Adult Learning Framework for Clinical Education. In: Mc Allister L, Lincoln M, Mc Leod S, D. M, editors. Facilitating Learning in Clinical Settings. Cheltenham: Stanley Thornes; 1997: I-26.

10. Higgs J, Mc Allister L. The Lived Experiences of Clinical Educators with Implications for their Preparation, Support and Professional Development. Learning in Health and Social Care, 2005; 4: I56-7I.

II. Costa D. Fieldwork Issues: Fieldwork Educator Readiness. Bethesda: American Occupational Therapy Association, 2007.

12. Mc Allister L. Finding Meaning and Preventing Burnout. In: Rose M, Best D, editors. Transforming Practice through Clinical Education, Professional Supervision and Mentoring. Edinburgh: Elsevier; 2005.

13. Dreyfus H, Dreyfus S. Mind over Machine: The Power of Human Intuition and Expertise in the era of the Computer. Newe York: Free Press, 1986.

14. Creswell J. Research Design: Quantitative, Qualitative and Mixed Methods Approaches. Third ed. Los Angeles: Sage, 2009.

I5. Laverty S. Hermeneutic Phenomenology and Phenomenology: A comparison of historical methodological considerations. International Journal of Qualitative methods, 2003; 2(3): 10.

16. Evans MJ, Hallett C. Living with Dying: a Hermeneutic Phenomenological Study of the work of Hospice Nurses. Journal of Clinical Nursing, 2007; 16: 742-51.

17. Bender D, Ewbank D. The Focus Group as a tool for Health Research: Issues in Design and Analysis. Health Transition Review, 1994; 4(I): 63-79.

18. Gibbs A. Focus groups. Social Research Update, 1997; 19(Winter): I-7.

19. P L, S L. Rethinking the focus group in media and communication reseach. Journal of Communications Research, 1996; 46(2): 79-98.

20. John W Creswell. Collecting Qualitative Data. In: John W Creswell, editor. Educational Research: Planning, Conducting, and Evaluating Quantitative and Qualitative Research. Fourth ed. Boston: Pearson; 2012: 204-35.
21. Amy Dohota, Dewey A. The sociogram: a useful tool in the Analysis of Focus Groups. Nursing Research, 2008; 57(4): 293-7.

22. Hennink M, Hutter I, Bailey A. Qualitative Research Methods. Ist ed. Los Angeles: Sage, 201 I.

23. Onwuegbuzie A, Dickinson W, Leech N, Zoran A. A Qualitative Framework for Collecting and Analyzing Data in Focus Group Research. International Journal of Qualitative methods, 2009; 8(3): I-20.

24. Graneheim B, Lundman B. Qualitative Content Analysis in Nursing Research: Concepts, Procedures and Measures to achieve Trustworthiness. Nursing Education Today, 2004; 24: 105-12.

25. Siegle D. "Trustworthiness". 20I I; Available from: <http:www. gifted.uconn.edu/siegle/research/qualitative/trust.htm $>$. [cited (2012 3.09.20I2)]

26. Kitzinger Jenny. The methodology of Focus Groups : the importance of interaction between the research participants. Sociology of Health and IIIness, 1994; 16(I): 103-2I.

27. Shenton A. Strategies for Ensuring Trustworthiness in Qualitative Research Projects. Education for information, 2004; 22: 63-75.

28. van Manen M. Researching Lived Experience: Science for Action Sensitive Pedagogy. New York: Suny Press, 1990.

29. Aiken F, Menaker L, Barsky L. Fieldwork Education: The future of Occupational Therapy depends on it. Occupational Therapy International, 200 I; 8(2): 86-95.

30. Bonello M. Fieldwork within the context of Higher Education: a Literature review. British Journal of Occupational therapy, 200I; 64(2): 93-9.

31. Forster K, Laurent R. How do we make Good Doctors into Good Teachers: A short course to support busy Clinicians to improve their Teaching Skills. Medical Teacher, 2013; 35: 4-7.

32. Higgs Joy, L MA. Educating Clinical Educators using a Model of the Experience of being a Clinical Educator. Medical Teacher, 2007; 29(2): 5 I-7.

33. De Witt P, Rothberg A, Bruce J. Occupational Therapy Manager's Role in and Perception of Clinical Education. South African Journal of Occupational Therapy, 2014; 44(I): 9-I4.

34. Canadian Physiotherapy Association. Clinical Education of Physiotherapy Students. 2008 November 2008. Report No.

35. American Speech-Language-Hearing Association. Knowledge, Skills and Training considerations for individuals serving as Supervisors. American Speech-Language-Hearing Association, 2013.

36. Hall MD. Identifying the Factors contributing to Canadian Physiotherapists to supervise Physiotherapy Students: Results from a National Survey. Alberta: University of Alberta, 2013.

37. Rodger S, Webb G, Devitt L, Gilbert J, Wrightson P, McMeeken J. Clinical Education and Practice Placements in the Allied Health Professions: An International Perspective. Journal of Allied Health, 2008; Spring 37(I).

38. Higgs J, Mc Allister L. Educating Clinical Educators using a Model of the Experience of being a Clinical Educator. Medical Teacher, 2007; 29(2): $51-7$.

Corresponding author

\section{Patricia De Witt}

Patricia.DeWitt@wits.ac.za

Department of Occupational Therapy

School of Therapeutic Sciences

Faculty of Health Sciences

University of the Witwatersrand

7 York Rd

Parktown

Johannesburg 2193 